\title{
Pathogenesis and clinical and economic consequences of postoperative ileus
}

This article was published in the following Dove Press journal:

Clinical and Experimental Gastroenterology

I July 2010

Number of times this article has been viewed

\section{Anthony J Senagore \\ Division of Colon and Rectal Surgery, University of Southern California Keck School of Medicine, Los Angeles, CA, USA}

\begin{abstract}
Postoperative ileus (POI) occurs frequently in patients undergoing major abdominal surgery; and only recently has there been renewed interest in understanding the pathogenesis, etiology, clinical manifestations, and clinical and economic consequences related to POI. This interest has been spurred by the potential access to novel pharmaceutical options for the management of POI. POI has a complex and multimodal pathophysiology including neurogenic, inflammatory, hormonal, and pharmacologic components. The clinical manifestations are clinically obvious and include abdominal distention, pain, nausea, vomiting, and inability to pass stools or tolerate a solid diet. Prolonged ileus has been defined as persistence of these symptoms for more than 4 days after major abdominal surgery; however the goal should be to reduce the incidence of these symptoms immediately after surgery. Clearly, the magnitude of the surgical stress and usage of opioid analgesia are the predominant causes of POI. The unappreciated sequelae of POI include increased rates in adverse surgical wound healing, reduced ambulation, atelectasis, pneumonia, urinary infections, and deep vein thrombosis. The secondary impact of these complications includes increased hospital length of stay, resource use, and healthcare costs. POI is common and the impact is underestimated. The addition of alvimopan as the first in class $\mu$-opioid inhibitor has demonstrated consistent benefit in reducing the incidence and impact of POI with reductions in length of hospital stay. POI is a common, and underappreciated complication of major abdominal surgery, and clinicians should be aware of the clinical care options, including novel pharmaceutical agents, that can successfully reduce the incidence of this postoperative complication.
\end{abstract}

Keywords: alvimopan, postoperative ileus, abdominal surgery

\section{Introduction}

Postoperative ileus (POI) is perceived as an unavoidable outcome of major abdominal surgery, primarily due to poorly understood multifactorial pathophysiology. ${ }^{1}$ POI is multifactorial in origin and causative factors include neurogenic, inflammatory, hormonal and pharmacologic influences. ${ }^{1}$ The neurogenic component relates to the pain induced neural reflexes which in turn result in sympathetic hyperactivity and inhibition of gastrointestinal (GI) motility. ${ }^{2,3}$ Surgical manipulation contributes further by activating a number of inflammatory cascades, primarily via the arachidonic acid cascade. These mediators cause the release of endogenous opioid peptides which further exacerbate the effects of exogenous opioid analgesics (administered for analgesia) on inhibition of bowel function. ${ }^{4-6}$ The hormonal influence on ileus is primarily mediated via corticotropin-releasing hormone as a response to the tissue trauma. ${ }^{7}$ POI may also occur following minimally invasive surgical procedures, despite obvious reductions in
Correspondence: Anthony J Senagore

I33। Winterwood Dr NE

Grand Rapids, MI, 49525

Email asenagore@sbcglobal.net
Clinical and Experimental Gastroenterology 2010:3 87-89

(C) 2010 Senagore, publisher and licensee Dove Medical Press Ltd.This is an Open Access article which permits unrestricted noncommercial use, provided the original work is properly cited. 
surgical trauma and manipulation of the bowel, possibly due to the effects of opioid analgesics mediated by stimulation of GI opioid receptors by exogenous opioids. ${ }^{8,9}$ The opioid negative effect on GI motility is believed to occur due to stimulation of $\mu$-opioid receptors in the bowel, leading to inertia in the gut. ${ }^{1,2}$ Relief of POI-related pain is a two edged sword as the surgeon balances adequate analgesia with additional impairment of GI motility. However the recent availability of alvimopan, a first in class oral $\mu$-opioid receptor antagonist, offers the potential of effective prophylaxis against postoperative ileus. POI is not life-threatening, but patients with POI typically experience substantial discomfort. ${ }^{10}$

Ileus after abdominal surgery can last a long time despite the use of what is referred to as a fast-track protocol, with early ambulation and gradual resumption of oral intake of liquids followed by solid food to accelerate a return to normal GI function. ${ }^{10,11}$ In 149 patients undergoing major abdominal surgery who were encouraged to ambulate and take oral liquids on the first postoperative day and eat solid food on the second postoperative day, more than 4 days elapsed before GI function returned to normal in half of the patients and $25 \%$ of patients had not regained normal GI function after more than 6 days had elapsed. ${ }^{10}$ Opioid analgesic use for postoperative pain has been shown to correlate with the time to return of normal bowel function after surgery. ${ }^{3}$

\section{Consequences}

Although not life-threatening, POI can prolong postoperative recovery, increase hospital length of stay and healthcare resource utilization and costs. ${ }^{12-15}$ The resultant abdominal distention increases the risk of hernia formation and wound dehiscence, while nausea and vomiting impacts resumption of enteral nutrition and increases the risk for malnutrition and impaired wound healing. The need for nasogastric decompression and prolonged venous access inhibit ambulation which may increase rates of pulmonary complications and thromboembolus. The morbidities associated with POI and the added care required places greater economic burdens on the healthcare system. The prolonged hospitalization associated with POI is an important issue at hospitals with a limited number of beds and high demand for inpatient services. Efforts to minimize POI and hospital lengths of stay without increasing the risk of post-discharge readmission have the potential to improve the financial bottom line for hospitals, private and governmental health insurers, and society at large. Approximately 161,000 Medicare recipients undergo major intestinal or rectal resection each year which consumes an estimated 1.8 million hospital days at a cost of
$\$ 1.75$ billion. ${ }^{16,17}$ Safely shortening this length of stay would produce significant dividends.

\section{Role of enhanced recovery programs}

A multi-modal approach has been developed to improve postoperative morbidity, including POI, in surgical patients. ${ }^{11,17,18}$ Patient education is an important component of fast-track protocols to accelerate recovery of normal GI function and should include an understanding of how important attempting early ambulation and early enteral nutrition is to the care plan. They should also understand the components of effective pain with both narcotic and non-steroidal combinations of oral medications. The newly available peripherally selective $\mu$-opioid receptor antagonist alvimopan offers an additional adjunct to the minimization of POI rates. ${ }^{10}$

\section{Potential role of alvimopan}

A recent pooled analysis of 3 of the prospective, randomized and blinded alvimopan trials confirmed that a $12 \mathrm{mg}$ dose provided optimal reduction in GI morbidity and return of GI function. ${ }^{19}$ These benefits are clinically relevant and important to clinicians when arranging discharge plans. ${ }^{20} \mathrm{An}$ interesting additional benefit of alvimopan was a significant decrease in the incidence of POI as a serious adverse event coupled with a reduction in the proportion of patients who had prolonged hospital stay or readmission. ${ }^{19}$ These benefits translated into a $50 \%$ reduction in the proportion of patients defined as having prolonged hospital stay.

Alvimopan has been generally well tolerated in the available trials without producing a negative impact on narcotic analgesic effects as demonstrated by pain scores. These trials all included a program of early oral nutrition and ambulation and therefore the reduction in time to discharge order written compared to placebo confirmed the additional benefit of alvimopan even in an enhanced recovery program.

\section{Conclusion}

The clinical and economic consequences of POI are substantial. Ensuring that patients undergoing major abdominal surgery understand the preoperative and postoperative care regimen can minimize these consequences.

\section{Disclosure}

The author declares no conflicts of interest.

\section{References}

1. Holte K, Kehlet H. Postoperative ileus: progress towards effective management. Drugs. 2002;62:2603-2615. 
2. Kehlet H, Holte K. Review of postoperative ileus. Am J Surg. 2001;182 Suppl 5A:3S-10S.

3. Holte K, Kehlet H. Postoperative ileus: a preventable event. Br J Surg. 2000;87:1480-1493.

4. Brix-Christensen V, Tonnesen E, Sanchez RG, et al. Endogenous morphine levels increase following cardiac surgery as part of the antiinflammatory response? Int J Cardiol. 1997;62:191-197.

5. Yoshida S, Ohta J, Yamasaki K, et al. Effect of surgical stress on endogenous morphine and cytokine levels in the plasma after laparoscopic or open cholecystectomy. Surg Endosc. 2000;14:137-140.

6. Kalff JC, Schraut WH, Simmons RL, et al. Surgical manipulation of the gut elicits an intestinal muscularis inflammatory response resulting in postsurgical ileus. Ann Surg. 1998;228:652-663.

7. Taché Y, Bonaz B. Corticotropin-releasing factor receptors and stress-related alterations of gut motor function. J Clin Invest. 2007;117:33-40.

8. Cali RL, Meade PG, Swanson MS, et al. Effect of morphine and incision length on bowel function after colectomy. Dis Colon Rectum. 2000;43:163-168.

9. Kraft M, Erstad BL, Matuszewski K. Improving postoperative ileus outcomes. US Pharm. 2005;30(4)(suppl):1-12. http://legacy.uspharmacist.com/oldformat.asp?url=ce/10193/default.htm.

10. Wolff BG, Michelassi F, Gerkin TM, et al. Alvimopan, a novel, peripherally acting mu opioid antagonist: results of a multicenter, randomized, double-blind, placebo-controlled, phase III trial of major abdominal surgery and postoperative ileus. Ann Surg. 2004;240: 728-735.
11. Delaney CP, Fazio VW, Senagore AJ, et al. 'Fast track' postoperative management protocol for patients with high co-morbidity undergoing complex abdominal and pelvic colorectal surgery. Br J Surg. 2001;88:1533-1538.

12. Collins TC, Daley J, Henderson WH, et al. Risk factors for prolonged length of stay after major elective surgery. Ann Surg. 1999;230:251-259.

13. Schuster TG, Montie JE. Postoperative ileus after abdominal surgery. Urology. 2002;59:465-471.

14. Chang SS, Baumgartner RG, Wells N, et al. Causes of increased hospital stay after radical cystectomy in a clinical pathway setting. $J$ Urol. 2002;167:208-211.

15. Lauer MA, Karweit JA, Cascade EF, et al. Practice patterns and outcomes of percutaneous coronary interventions in the United States: 1995 to 1997. Am J Cardiol. 2002;89:924-929.

16. Woods MS. Postoperative ileus: dogma versus data from bench to bedside. Perspect Colon Rectal Surg. 2000;12:57-76.

17. Delaney CP. Clinical perspective on postoperative ileus and the effect of opiates. Neurogastroenterol Motil. 2004;16 Suppl 2:61-66.

18. Kehlet H, Dahl JB. Anaesthesia, surgery, and challenges in postoperative recovery. Lancet. 2003;362:1921-1928.

19. Delaney CP, Wolff BG, Viscus ER, et al. Alvimopan, for postoperative ileus following bowel resection: a pooled analysis of phase III studies. Ann Surg. 2007;245:355-363.

20. Bungard TJ, Kale-Pradhan PB. Prokinetic agents for the treatment of postoperative ileus in adults: a review of the literature. Pharmacotherapy. 1999;19:416-423.
Clinical and Experimental Gastroenterology

\section{Publish your work in this journal}

Clinical and Experimental Gastroenterology is an international, peerreviewed, open access journal, publishing all aspects of gastroenterology in the clinic and laboratory, including: Pathology, pathophysiology of gastrointestinal disease; Investigation and treatment of gastointes tinal disease; Pharmacology of drugs used in the alimentary tract;

\section{Dovepress}

Immunology/genetics/genomics related to gastrointestinal disease. This journal is indexed on CAS. The manuscript management system is completely online and includes a very quick and fair peer-review system. Visit http://www.dovepress.com/testimonials.php to read real quotes from published authors. 